\title{
Kernos
}

Revue internationale et pluridisciplinaire de religion grecque antique

$34 \mid 2021$

Varia

\section{Athena Itonia: Geography and Meaning of an Ancient Greek War Goddess}

\section{Audrey Vasselin}

\section{(2) OpenEdition}

\section{Journals}

Édition électronique

URL : https://journals.openedition.org/kernos/3966

DOI : 10.4000/kernos.3966

ISSN : 2034-7871

\section{Éditeur}

Centre international d'étude de la religion grecque antique

\section{Édition imprimée}

Date de publication : 31 décembre 2021

Pagination : 301-302

ISBN : 978-2-87562-305-8

ISSN : 0776-3824

Référence électronique

Audrey Vasselin, «Athena Itonia: Geography and Meaning of an Ancient Greek War Goddess », Kernos [En ligne], 34 | 2021, mis en ligne le 31 décembre 2021, consulté le 15 mars 2023. URL : http:// journals.openedition.org/kernos/3966 ; DOI : https://doi.org/10.4000/kernos.3966

Ce document a été généré automatiquement le 15 mars 2023.

Tous droits réservés 


\title{
Athena Itonia: Geography and Meaning of an Ancient Greek War Goddess
}

\author{
Audrey Vasselin
}

\section{RÉFÉRENCE}

Gerald V. LALONDE, Athena Itonia: Geography and Meaning of an Ancient Greek War Goddess, Leiden, Brill, 2019. 1 vol. xx + 329 p. (Religions in the Graeco-Roman World, 191). ISBN : 978-90-04-41640-6.

1 Comme son titre l'indique, l'ouvrage de Gérard Lalonde (G.L.) a pour ambition d'aborder les cultes d'Athéna Itōnia selon une approche spatiale. L'étude est divisée en quatre parties qui correspondent aux quatre régions étudiées - Thessalie, Béotie, Attique et Amorgos. Le cadre temporel s'étend de la préhistoire grecque jusqu'à l'époque romaine, ce qui permet à l'A. de poser la question de l'origine du culte et son évolution. Dans cette optique est convoqué un vaste corpus qui inclut les sources archéologiques ainsi qu'une documentation épigraphique et littéraire. Ce n'est certes pas la première fois que cette divinité reçoit l'attention des historiens, mais c'est la première fois qu'une monographie lui est entièrement consacrée. Il ne s'agit pas, pour G.L., de renouveler l'historiographie sur le sujet, mais de la réévaluer à la lumière des découvertes archéologiques $\mathrm{du} \mathrm{xx}^{\mathrm{e}}$ siècle. Le volume comporte plusieurs cartes et illustrations : la photographie d'un horos (Agora I 7047) sur lequel est gravé le nom de la déesse, une statuette en bronze archaïque la figurant, ainsi que 32 pièces provenant, pour la plupart, de Thessalie.

2 La première partie de l'ouvrage s'ouvre sur une étude étymologique de l'épithète Itōnia. G.L. analyse la riche documentation qui embrasse une variété de noms formés sur le radical Iton- : cela comprend les deux toponymes Itōn et Itōnos, le héros local Itônos, le mois Itônios et, enfin, la fête des Itōnia. Les noms issus de cette nomenclature 
« itônienne » sont autant d'indices qui prouveraient l'origine thessalienne de la déesse. L'A. s'intéresse ensuite au caractère militaire d'Athéna Itōnia. Les liens que celle-ci entretenait avec la res militaris, et plus précisément avec la cavalerie, auraient contribué à son implantation durable dans toute la Thessalie. Le reste du chapitre est dévolu à l'épineuse question de la géographie des cultes thessaliens d'Athéna Itōnia. Les recherches archéologiques et topographiques n'ont pu qu'exhumer le sanctuaire situé dans le district de Thessaliotis, alors que les sources évoquent bien d'autres localités.

G.L. poursuit son enquête en Béotie. Il tente, en premier lieu, d'établir les circonstances de l'adoption du culte par les Béotiens. L'A. suppose que ces derniers l'auraient importé de la Thessalie lors de leurs migrations vers la région qui porte leur nom. Il consacre, ensuite, l'essentiel du chapitre à l'étude de l'Itonéion fondé près de Coronée, dont nous ignorons l'emplacement exact. Ce sanctuaire était le lieu de réunion de la confédération pan-béotienne, qui venait notamment y célébrer les Pamboiōtia. C'est l'occasion, pour G.L., de faire ressortir les liens étroits tissés entre le culte d'Athéna Itōnia et le développement des ligues béotiennes tout au long de l'histoire de la région. On aurait cependant aimé qu'il examine plus profondément les relations entre les autres cultes d'Athéna - à Akraiphia, Alalkoménée, Haliarte - et celui d'Athéna Itōnia.

G.L. quitte les terres béotiennes pour se rendre en Attique où un culte d'Athéna Itōnia est attesté par quatre brèves références épigraphiques, datées de l'époque classique. La localisation de son sanctuaire demeure aujourd'hui encore un mystère que les sources - tant matérielles que textuelles - peinent à dissiper. En s'appuyant sur les relevés topographiques d'une part, et sur l'évocation d'une " porte itônienne » dans l'Axiochos du Pseudo-Platon d'autre part, G.L. suit l'hypothèse formulée des décennies plus tôt par John Travlos sur l'emplacement du sanctuaire au sud-est de l'asty, près du Cynosarge. Le contexte de l'adoption du culte à Athènes est lui aussi incertain. Pour G.L., le culte serait arrivé en même temps que la cavalerie thessalienne, avec qui Pisistrate avait noué une alliance lors des premières années de sa tyrannie. Même si l'hypothèse est intéressante, elle n'en reste pas moins fortement spéculative car aucune source n'évoque les débuts du culte athénien. Il est d'ailleurs curieux que l'A. ait préféré traiter la question de l'origine athénienne d'Athéna Itōnia - posée par quelques historiens dont $\mathrm{N}$. Robertson - en appendice, plutôt qu'à la suite de sa réflexion sur le thème.

5 L'ouvrage se clôt sur l'étude des cultes de la déesse itônienne dans l'île d'Amorgos. Les connaissances que nous avons de ces cultes reposent essentiellement sur une série de stèles d'époque hellénistique. Les cités d'Arkésine et de Minoa avaient inscrit sur cellesci les décrets honorant les archontes qui avaient généreusement financé les festivités des Itōnia. Malgré cette abondance documentaire, les historiens ignorent tout de sa chronologie et, surtout, de son origine. Certains ont argué une filiation béotienne ou athénienne mais G.L. préfère laisser la question ouverte en raison du manque de sources. En revanche, les décrets honorifiques mettent en lumière la grande richesse du culte d'Athéna Itōnia. Pour l'A., le commerce maritime serait la source d'une telle fortune, comme en témoigneraient les nombreuses traces épigraphiques qui mentionnent des actes de piraterie à l'encontre d'Amorgos à la même période. Athéna Itōnia aurait protégé les habitants de l'île, et tout particulièrement, les navigateurs, des agressions des pirates; en retour, les habitants lui auraient dédié de somptueuses offrandes pour la remercier. 


\section{AUTEURS}

\section{AUDREY VASSELIN}

Université Paris 1 - Panthéon Sorbonne 